\title{
Along the Print
}

Grass-of-Parnassus grow along the path to our swamp, their waxy petals like stars

bursting white above the black mud, and narrow petals of yellow flowers we call peanut butters, because we never learned their real name.

Footprints of night creatures linger in the soft earth, draw me in-

a record of those who passed unseen

so close to our place.

Rocks form stepping-stones to my sister's boarding house where I build a room without a roof, furnish it with a rug of horsetail.

Nearby my brother plays the superhero, slashing at us with his willow branch sword.

Tomorrow is following us, but we are children, not carrying coats or coins or memories yet.

We still believe the black spruce are lords of everything. 